\title{
Gestão costeira integrada: análise da compatibilidade entre os instrumentos de uma política pública para o desenvolvimento da maricultura e um plano de gerenciamento costeiro no Brasil *
}

\section{Integrated coastal zone management: a compatibility review between a public policy for the mariculture development and a coastal zone management plan in Brazil}

\author{
Luiz Fernando de Novaes Vianna ${ }^{\circledR,}, 1$ Jarbas Bonetti ${ }^{2}$, Marcus Polette ${ }^{3}$
}

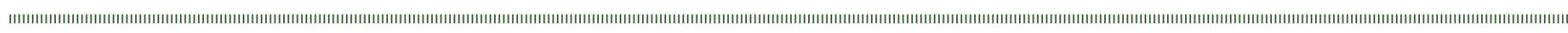

\section{RESUMO}

Em 2005 o Brasil lançou o Programa Nacional de Desenvolvimento da Maricultura em Águas da União através da Secretaria Especial de Aquicultura e Pesca (Seap), hoje Ministério da Pesca e Aquicultura (MPA), com o objetivo de ordenar a atividade e promover sua expansão. Foi a primeira iniciativa no País visando implementar uma política pública direcionada especificamente para o setor aquícola. O estado de Santa Catarina, pioneiro na adoção do programa, necessitou enquadrar-se nas diretrizes impostas pela legislação vigente para elaborar e implantar os Planos Locais de Desenvolvimento da Maricultura (PLDM), principal instrumento do programa. Para isso, foi necessário compatibilizar os PLDMs com o Plano Estadual de Gerenciamento Costeiro de Santa Catarina (Gerco-SC). Isso foi feito por meio dos instrumentos Zoneamento Ecológico Econômico Costeiro (ZEEC) e Plano de Gestão da Zona Costeira (PGZC). O PLDM é um instrumento de planejamento participativo para auxiliar na delimitação dos parques aquícolas em águas de domínio da Uniấo. O ZEEC, por seu turno, é um instrumento de ordenamento territorial, monitoramento, licenciamento e fiscalizaçáo que opera em consonância com as diretrizes da Política Nacional de Gerenciamento Costeiro. Também deve ser elaborado de forma participativa e estabelecer diretrizes quanto aos usos proibidos, permitidos ou estimulados na zona costeira. Já o PGZC apresenta propostas de açáo com metas bem definidas, atores responsáveis e envolvidos na execução, área de atuação, prazos, custo aproximado e fontes potenciais de recursos. Visa ordenar as diferentes atividades e usos do território costeiro e marinho, promover o desenvolvimento socioeconômico sustentável e garantir a conservação dos recursos naturais. Neste artigo foi feita uma análise da evolução histórica da implementação dessas duas políticas públicas no estado de Santa Catarina, Brasil, através dos seus instrumentos. O objetivo foi avaliar a compatibilidade entre as políticas de ordenamento da maricultura e o gerenciamento costeiro através da adoção dos instrumentos PLDM, ZEEC e PGZC. Constatou-se que são instrumentos tecnicamente eficientes, mas que na prática vêm sendo implementados de forma burocrática e pouco integrada, porque o Estado ainda não possui estrutura compatível com as necessidades logísticas, técnicas e metodológicas para conduzir integralmente o processo. Em relação à maricultura, o processo participativo do zoneamento dos parques aquícolas nos PLDMs mostrou-

@ - Corresponding author:vianna@epagri.sc.gov.br

1 - Empresa de Pesquisa Agropecuária e Extensáo Rural de Santa Catarina (Epagri). Rodovia Admar Gonzaga, 1.347, Itacorubi, Caixa Postal 502, CEP: 88034-901, Florianópolis, SC, Brasi

2 - Universidade Federal de Santa Catarina. Campus Universitário Reitor João David Ferreira Lima, Trindade - Florianópolis, Santa Catarina, Brasil, CEP: $88040-970$

3 - Universidade do Vale do Itajai - Rua Uruguai, 458, Centro, Itajai, Santa Catarina, Brasil, CEP: 88302-202 
se eficiente setorialmente, fortalecendo as associaçóes de maricultores e o setor de pesquisa e extensão rural de Santa Catarina no processo decisório. Já o processo participativo do GERCO-SC, por ser multissetorial e mais complexo, precisa evoluir, pois mantém o aspecto político-institucional e tecnocrático de gestão. Como produto efetivo, o Estado conta hoje com o ZEEC e o PGZC constituídos de direito, e os PLDMs de fato e de direito. Isso significa que, apesar de os instrumentos do GERCO-SC existirem legalmente, sua implementação está comprometida pela necessidade de solucionar conflitos vindos desde sua origem. Enquanto isso, os PLDMs já são efetivos, através de delimitação dos parques aquícolas no mar, ordenamento e licitaçáo das áreas aquícolas individuais de produção, elaboração de uma base de dados georreferenciados, desenho de um plano de monitoramento e sistema de gestão. Dessa forma, os PLDMs devem orientar o setor aquícola na avaliaçáo do potencial da zona costeira para a atividade e auxiliar no planejamento e na escolha de áreas por intermédio de propostas de setorização de parques e áreas aquícolas. Todavia, devem igualmente estar enquadrados nos instrumentos ZEEC e PGZC do Gerco-SC, com revisóes técnicas e institucionais baseadas em processo participativo e integrado, em conformidade com a legislação e seguindo as tendências democráticas de gestão costeira integrada.

Palavras-chave: Planos Locais de Desenvolvimento da Maricultura; PLDM; Zoneamento Marinho; Instrumentos de Gestão Costeira.

\section{ABSTRACT}

In 2005 Brazil released the National Program for the Development of Marine Aquaculture in Union Waters through the Special Secretariat of Aquaculture and Fisheries (Seap), now Ministry of Fisheries and Aquaculture (MPA). Its aim was to order the activity and promote its expansion. It was the first initiative in the country seeking the implementation of a public policy specifically directed to the aquaculture sector. The state of Santa Catarina, a pioneer in the adoption of the program, needed to fit into the guidelines imposed by legislation in order to develop and implement the Local Plans for the Development of Marine Aquaculture (PLDM), its most important instrument. This required PLDM to be compatible with the State Coastal Management Plan of Santa Catarina (Gerco-SC), through the instruments Coastal Ecological and Economic Zoning (ZEEC) and Plan of Coastal Zone Management (PGZC). The PLDM is a participatory planning tool to aid in the delineation of aquaculture parks in waters belonging to Brazil. The ZEEC, in turn, is a tool for planning, monitoring, licensing, and supervision that operates in accordance with the guidelines of the National Coastal Management Policy. It should also be elaborated in a participatory process and establish guidelines to determine prohibited, permitted or encouraged uses in the coastal zone. Finally, the PGZC presents proposals for actions with clearly defined goals, key actors and others involved in the execution, area of intervention, agenda, approximate cost and potential sources of resources. It aims to order the different activities and uses of coastal and marine territories, promote the sustainable socioeconomic development and ensure the conservation of natural resources. In this paper an analysis of the historical evolution of the implementation of these two policies in Santa Catarina was carried out considering their instruments. The objective was to evaluate the compatibility between the planning policies for marine aquaculture and coastal management in Santa Catarina through the implementation of the instruments PLDM, ZEEC and PGZC. It was found that these instruments are technically efficient, but in practice they have been implemented in a bureaucratic and insufficient integrated way because the state does not have a structure compatible with the logistical, technical or methodological needs to totally conduct the process. In relation to marine aquaculture, the participatory process of zoning the aquaculture parks in PLDM proved to be efficient by sector, strengthening the associations of shell fishermen and research and extension sectors of Santa Catarina in the decision practice. On the other hand, the multisectoral participatory process of Gerco-SC is still incipient and maintains a political, institutional and technocratic nature in the management efforts. As an effective product, the state now has the ZEEC and PGZC established by law and the PLDM constituted in fact. This means that the instruments were developed in Gerco but lack implementation, while PLDM's are already effective through the delimitation of the offshore aquaculture parks, planning and procurement of individual aquaculture production areas, development of a georeferenced database, and design of a monitoring plan and management system. The PLDM should guide the aquaculture industry in assessing the potential of the coastal zone for the activity and assist in planning and selecting aquaculture areas. However, it must also be associated to the Gerco-SC' ZEEC and PGZC instruments through a participatory and integrated process in accordance with the law and following the democratic tendencies of integrated coastal management.

Keywords: Local Plans for Development of Mariculture; PLDM; Marine Zoning; Instruments of Coastal Zone Management.

\section{INTRODUÇẤO}

OPrograma Nacional de Desenvolvimento da Maricultura em Águas da União (Seap, 2005) é uma política pública de gestão da zona costeira com foco setorial na maricultura. Foi concebida pela Secretaria Especial de Aquicultura e Pesca da Presidência da República (Seap), atual Ministério da Pesca e Aquicultura (MPA), que definiu como principal instrumento de açáo os Planos Locais de Desenvolvimento da Maricultura (PLDM). Sua base legal consiste do Decreto Federal 4.895, de 25/11/2003 e instruçóes normativas ministeriais e interministeriais.
O Decreto 4.895/2003 e a Instrução Normativa Interministerial 06/2004 tratam da autorização de uso dos espaços físicos de corpos de água de domínio da Uniāo para fins de aquicultura e apresentam a base conceitual, diretrizes, responsabilidades institucionais, trâmite processual e sistema de informação para gerenciar os processos. Já as instruçóes normativas da Seap e do MPA estão centradas na elaboração dos PLDMs. A IN 17/2005 traz o Roteiro para Elaboração dos PLDM, que foi atualizado pela IN $11 / 2008$ com a publicação do Termo de Referência para Elaboração dos PLDM.

Numa perspectiva mais abrangente e integrada de gestáo costeira, a Constituição Federal definiu, em seu artigo 225 , a zona costeira como patrimônio nacional, enquanto 
a lei 7.661 instituiu o Plano Nacional de Gerenciamento Costeiro (PNGC). Gestão costeira é um processo dinâmico e complexo que compatibiliza o uso e a ocupação da zona costeira de maneira organizada, considerando os mais diversos interesses econômicos, sociais, políticos e conservacionistas (Polette \& Silva, 2003). Sua dinâmica pode ser compreendida, sob um aspecto didático, quando representada por etapas que se intercalam de forma cíclica num processo contínuo e retroalimentado de diagnóstico, planejamento, implementação e avaliação. Já a complexidade pode estar associada à escala de abrangência de cada programa, podendo levar entre 8 e 15 anos para completar um ciclo em escala nacional, ou a metade desse tempo, se implementado em uma área costeira específica, como uma baía ou uma cidade (Olsen et al., 1999).

O PNGC está baseado em instrumentos de gestão. Nesse sentido, Polette \& Silva (2003) fizeram uma tentativa de compatibilizar os instrumentos previstos na resolução no 5 da Comissão Interministerial para os Recursos do Mar (CIRM) (CIRM, 1997) com os estágios do ciclo de gestão propostos por Olsen et al. (1999), concluindo que os instrumentos brasileiros abrangem boa parte do processo de gestão. Segundo os autores, no entanto, é necessário que esses instrumentos sejam aplicados de forma organizada e sigam os estágios do ciclo.

O PNGC possui nove instrumentos, quatro gerenciais e cinco operacionais. Os gerenciais são os Planos Nacional, Estaduais e Municipais de Gerenciamento Costeiro e ainda o Plano de Ação Federal em Gerenciamento Costeiro (PAF), no qual estáo definidas as responsabilidades e procedimentos institucionais das políticas estaduais e municipais de gestão costeira, obedecendo à estrutura hierárquica União-EstadoMunicípio. Os operacionais são Zoneamento Ecológico Econômico Costeiro (ZEEC), Plano de Gestáo da Zona Costeira (PGZC), Sistema de Informaçóes do Gerenciamento Costeiro (Sigerco), Sistema de Monitoramento Ambiental da Zona Costeira (SMA-ZC) e Relatório da Qualidade Ambiental da Zona Costeira (RQA-ZC), que auxiliam na implementação do plano com açốes concretas de gestão da zona costeira.

Considerada um patrimônio do povo brasileiro, a zona costeira é composta por um complexo mosaico ecossistêmico do qual fazem parte manguezais, praias, dunas, cordóes litorâneos, costốes rochosos, restingas, marismas, mata atlântica, lagunas costeiras e estuários. Esses ecossistemas sofrem constantes pressōes antrópicas associadas aos vetores de desenvolvimento como as atividades portuária, petrolífera, química, pecuária, pesqueira, agrícola, turística, urbanística e de aquicultura. Cerca de $23,5 \%$ da população do país reside nos 400 municípios costeiros, onde se concentram 16 das 28 regiôes metropolitanas, das quais três estão em Santa Catarina: Norte/Nordeste Catarinense, Foz do Rio Itajaí e Florianópolis (Zamboni \& Nicolodi, 2008).

É para gerenciar os conflitos gerados por essa dinâmica socioambiental e garantir uma qualidade mínima na zona costeira que Gerco-SC e PLDM devem estar integrados. Essa integraçâo passa por um processo político-social que envolve conflitos de interesses e ajustes institucionais, ordenados por um sistema normativo e legal que deve estar baseado em princípios técnico-científicos, democráticos e éticos.
A gestão participativa é fundamental num processo dessa natureza, uma vez que favorece consenso entre conflitos, diálogo institucional, transparência legal e justificativa técnica e científica num espaço de discussão aberto para a sociedade.

Este artigo apresenta uma avaliação da experiência de implantação dos PLDMs em Santa Catarina. Inicialmente é feita uma caracterização da área de estudo e são apresentados os conceitos, os instrumentos e as ferramentas adotados na elaboração dos planos com destaque para as áreas aquícolas, parques aquícolas e áreas de preferência, que são as unidades espaciais de gestão da atividade previstas no decreto 4.895/2003. Também o ZEEC e o PGZC, que são instrumentos de gestão do Gerco-SC e o Sistema de Informações Geográficas para Participação Pública (SIGPP), ferramenta adotada metodologicamente de acordo com terminologia proposta por Mello (2003). Em seguida, é feito um histórico do gerenciamento costeiro e do processo de instalação da atividade de maricultura, partindo dos primeiros diagnósticos da zona costeira e das pesquisas sobre espécies com potencial para produção comercial.

Esse histórico é considerado fundamental para facilitar a avaliação comparativa entre as duas políticas públicas, suas interaçôes, deficiências e potencialidades, como fizeram Polette et al. (2004) e Asmus et al. (2004) sobre a gestão costeira no Brasil à época. Finalmente, são apresentadas algumas consideraçôes sobre a forma de integração dos planos com os instrumentos através do SIG-PP em Santa Catarina.

\section{2. ÁREA DE ESTUDO}

O Estado de Santa Catarina está localizado na Regiáo Sul do Brasil (Figura 1). Possui aproximadamente $1.874 \mathrm{~km}$ de linha de costa, e em determinadas localidades as atividades sociais, culturais e econômicas pressionam os ecossistemas costeiros e geram conflitos de interesses pelo seu uso e ocupação.

O Gerco-SC divide a zona costeira em 5 setores, que abrangem 36 municípios (Figura 2). Para fins de maricultura, destacam-se os setores Norte, Centro-Norte e Central. O primeiro caracteriza-se por concentrar atividades secundárias e terciárias (indústrias, comércio e serviços). O setor CentroNorte se destaca pelo potencial turístico, mobiliário e portuário, e o Central possui a economia voltada para comércio, serviços e atividades vinculadas ao turismo, que, juntas, somam $60 \%$ do seu PIB. É neste último ainda que está concentrada a maior parte da populaçáo da zona costeira catarinense, com pouco mais de 900 mil pessoas em apenas seis municípios já conurbados: Biguaçu, Florianópolis, Governador Celso Ramos, São José, Palhoça e Tijucas (SPG, 2010a).

A maricultura é uma das atividades econômicas de destaque no estado, já que $95 \%$ dos moluscos (ostras, mexilhóes e vieiras) produzidos no Brasil são cultivados em fazendas marinhas localizadas em suas baías, enseadas e estuários (Zamboni \& Nicolodi, 2008). Por causa disso, é também uma das atividades que concorre pelo uso do espaço marinho. Essa concorrência apresenta-se tanto pela necessidade de um ambiente limpo, com qualidade ambiental 

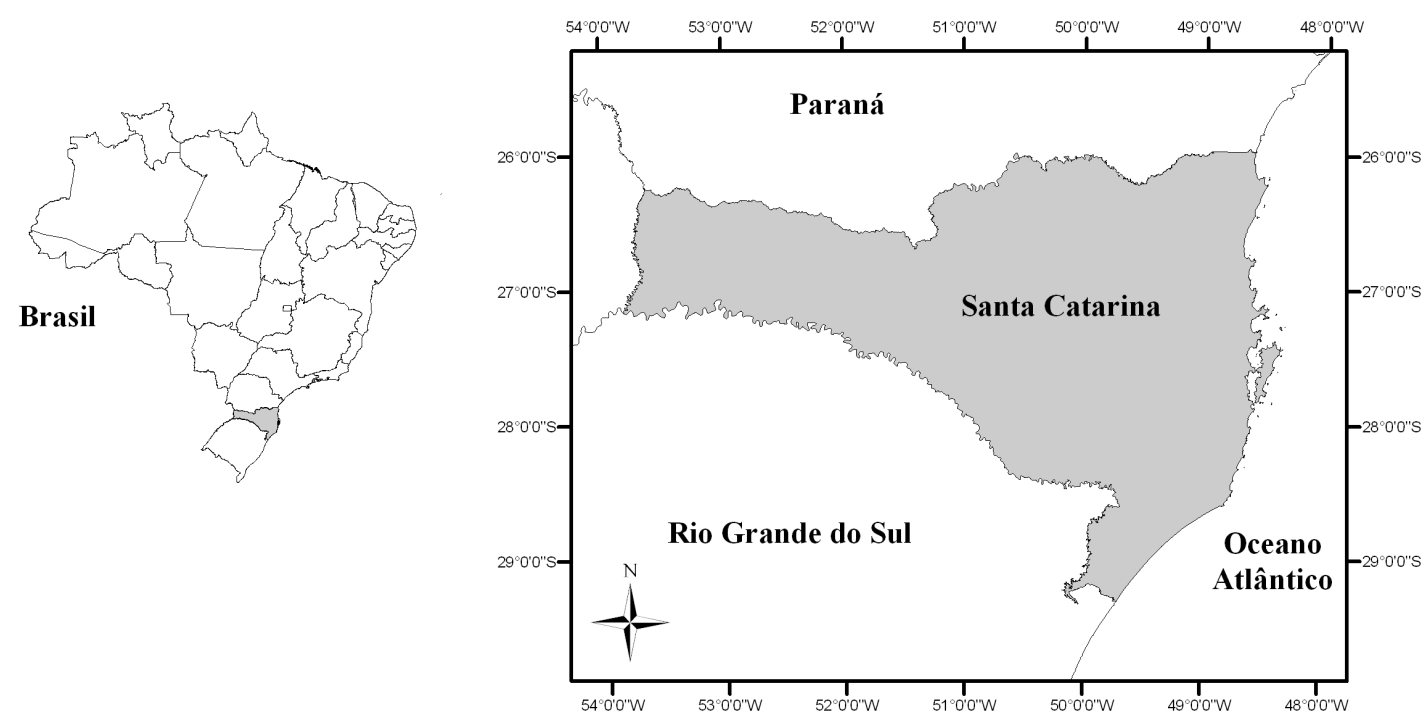

Figura 1. Área de estudo: Localização do estado de Santa Catarina no sul do Brasil.

Figure 1. Area of study: location of the State of Santa Catarina in southern Brazil.

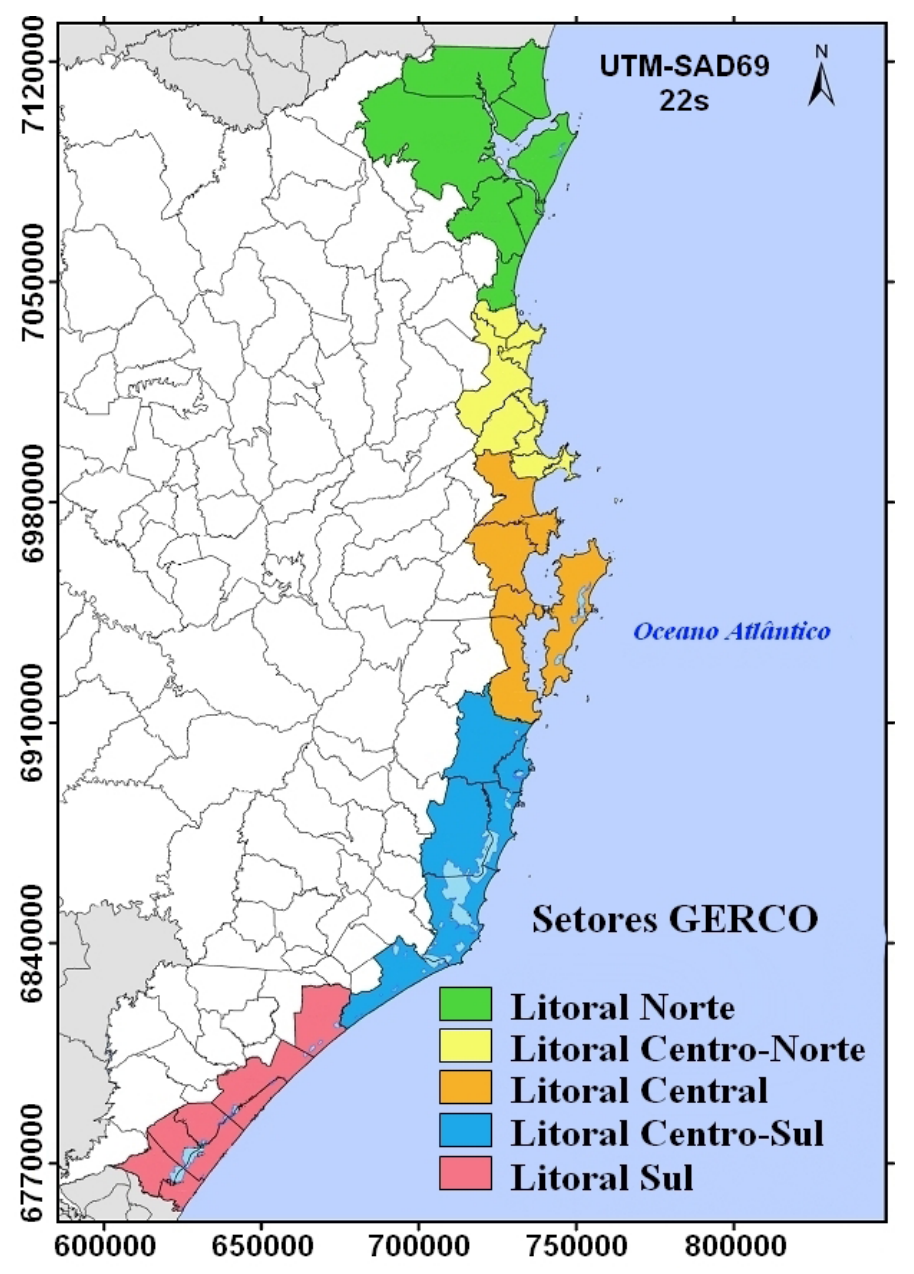

Figura 2. Setores da zona costeira de Santa Catarina: Litoral Norte (verde), Litoral Centro-Norte (amarelo), Litoral Central (laranja), Litoral Centro-Sul (azul), Litoral Sul (rosa). Fonte: SPG (2010a).

Figure 2. Sectors of the coastal zone of Santa Catarina: North Coast (green), North-Central Coast (yellow), Central Coast (orange), SouthCentral Coast (blue), South Coast (pink). Source: SPG (2010a). e sanitária compatível com a produção de alimentos, quanto pela poluiçáo visual e disputa por espaço com outras atividades, como navegação, lazer e pesca.

Nos setores Centro-Norte e Central estão os municípios de maior expressão em relação aos produtos oriundos da maricultura catarinense. No ano de 2010 foi registrada a maior produção de moluscos da história, com 15.635 toneladas, das quais 13.722 eram de mexilhóes, 1.908 de ostras e 5,4 de vieiras. Em relação aos mexilhóes, tiveram destaque os municípios de Palhoça, Penha e Bombinhas, com 56,9\%, 14,7\% e 6,8\% da produção respectivamente. Já os municípios com produção mais significativa de ostra foram Florianópolis $(77,4 \%)$, Palhoça (14\%) e São José (6,6\%) (Epagri, 2010).

A pressão demográfica no setor Central indica cenários de conflitos tanto na faixa terrestre (especulação imobiliária/ planejamento urbano/conservaçáo ambiental) quanto na faixa marinha (maricultura/turismo/saneamento). Esses conflitos estão associados à ocupação urbana, que faz com que a atual taxa de urbanizaçáo seja de $96 \%$, ou seja, cerca de 860 mil pessoas que vivem nesse setor estão nas cidades. O reflexo pode ser percebido nos problemas sanitários, visto que apenas 34,4\% dos domicílios estão ligados à rede pública de coleta de esgoto e não há políticas de saneamento que atuem para melhorar esse quadro e garantir condiçóes de crescimento. Há ainda uma grande parte de domicílios com tratamento individual $(55,1 \%)$, mas não se tem conhecimento suficiente sobre a eficiência desses sistemas e seu impacto no meio ambiente (SPG, 2010a).

A contaminação dos recursos hídricos também é um problema. Defensivos agrícolas utilizados à montante das áreas de captação dos mananciais, dejetos urbanos lançados nos rios e galerias pluviais e extrativismo vegetal comprometem a qualidade da água, contribuem para o aumento do deficit hídrico e influenciam a qualidade da água do mar (SPG, 2010a). Dados de balneabilidade da Fundação Estadual de Meio Ambiente (Fatma) indicaram dezesseis 
praias com histórico de contaminação por coliformes fecais superior a 50\% do tempo entre os anos de 2009 e 2010 (Fatma, 2012).

\section{OBJETIVOS}

Diante dos conflitos apresentados e da necessidade de gerenciá-los, o objetivo deste trabalho é avaliar a compatibilidade entre as políticas de ordenamento da maricultura e o gerenciamento costeiro em Santa Catarina com a implementação dos instrumentos PLDM, ZEEC e PGZC. Com isso, busca-se contribuir, de forma crítica e propositiva, com a melhoria contínua na integração dos instrumentos de gestáo apresentados para que esse processo se estabeleça de forma participativa e integrada no longo prazo.

\section{CONCEITOS, INSTRUMENTOS E FERRAMENTAS}

\section{1. Áreas aquícolas, parques aquícolas e áreas de preferência}

O Decreto 4.895, de 25 de novembro de 2003, dispóe sobre a autorização de uso de espaços físicos de corpos de água de domínio da União para fins de aquicultura. Nele estáo definidos os conceitos das unidades de mapeamento aquícola para delimitação de áreas aquáticas para fins de aquicultura (Figura 3). Essas unidades são denominadas:

Áreas Aquícolas: "espaço físico contínuo em meio aquático, delimitado, destinado a projetos de aquicultura, individuais ou coletivos".
Parques Aquícolas: "espaço físico continuo em meio aquático, delimitado, que compreende um conjunto de áreas aquicolas afins, em cujos espaços físicos intermediários podem ser desenvolvidas outras atividades compativeis com a prática da aquicultura".

Faixas ou Áreas de Preferência: "aquelas cujo uso será conferido prioritariamente a determinadas populaçôes, na forma estabelecida neste Decreto". O Decreto define como preferentes "as populaçôes tradicionais, atendidas por programas de inclusão social”.

Além de apresentar esses conceitos, o Decreto atribui ao MPA a responsabilidade pela delimitação e localização dos parques aquícolas e das áreas de preferência, com anuência prévia do Ministério do Meio Ambiente (MMA), da Autoridade Marítima, do Ministério do Planejamento, Orçamento e Gestão e da Agência Nacional de Águas (ANA), já prevendo ações interinstitucionais. Em relação às Áreas Aquícolas, a Instrução Normativa Interministerial $n^{\circ}$ 6, de 28 de maio de 2004, também atribui ao MPA, ou à entidade por ele delegada, a responsabilidade por sua distribuição e delimitação dentro dos Parques Aquícolas.

\subsection{Programa Nacional de Desenvolvimento da Maricultura em Águas da Uniáo}

O Programa Nacional de Desenvolvimento da Maricultura em Águas da União (Seap, 2005) foi criado pelo governo federal para "auxiliar no planejamento da maricultura levando em conta que o Brasil é um país com dimensóes continentais, partindo da ideia de apoiar as potencialidades locais considerando as características ambientais de cada regiäo". Como instrumento de planejamento, foram adotados

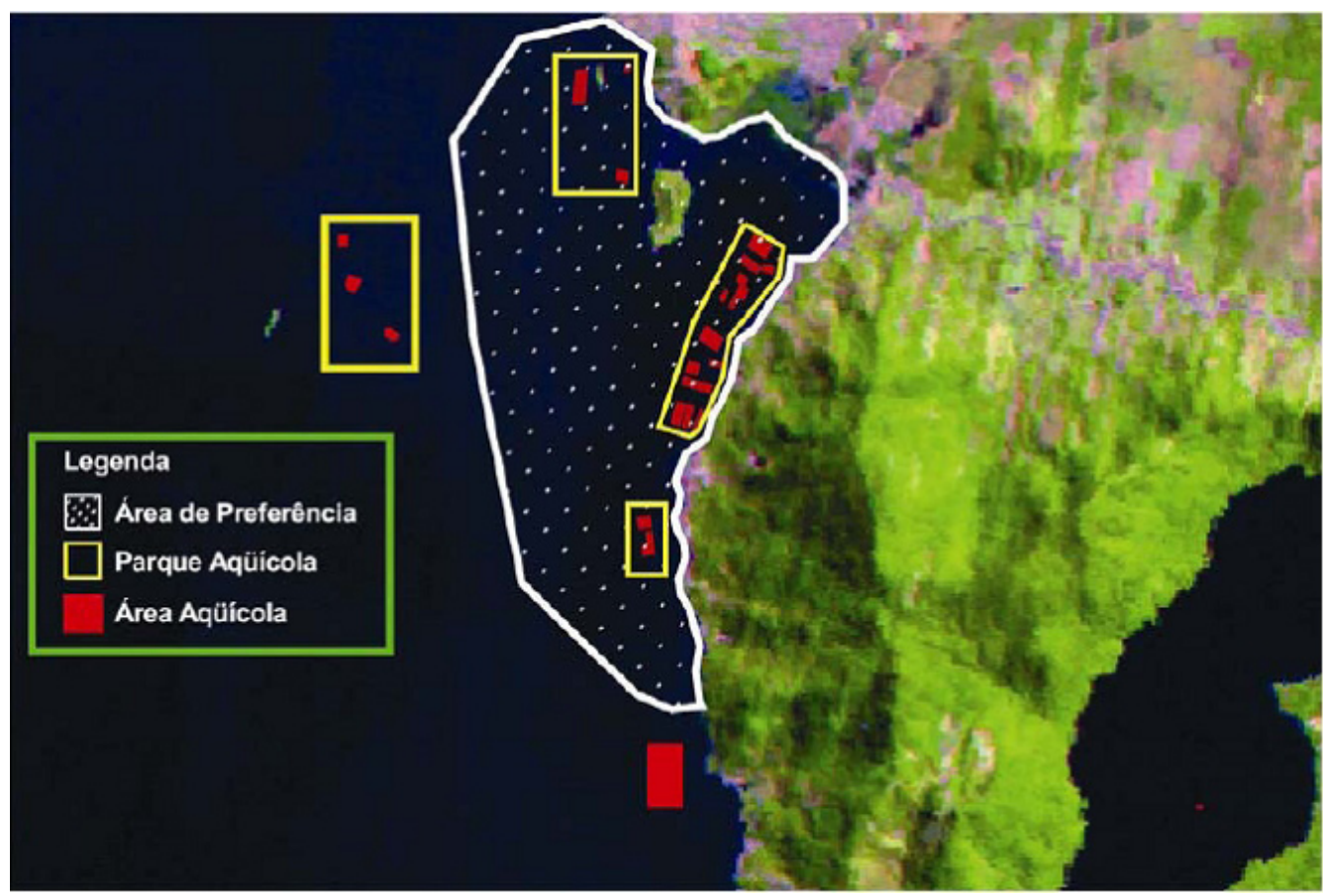

Figura 3. Representação das unidades de mapeamento aquícola em Santa Catarina: Áreas Aquícolas (vermelho), Parques Aquícolas (amarelo) e Áreas de Preferência (branco). Fonte: Seap (2005).

Figure 3. Representation of aquaculture mapping units in Santa Catarina: Sea Farms (red), Aquaculture Areas (yellow) and Areas of Preference (white). Source: Seap (2005). 
os Planos Locais de Desenvolvimento da Maricultura (PLDM) com o objetivo de "planejar o desenvolvimento do setor utilizando ferramentas de microzoneamento numa escala municipal, ou, quando for o caso, promover esse planejamento para baías, lagoas, reservatórios, estuários".

Segundo a Instrução Normativa da Seap no 17, de 22 de setembro de 2005, os Planos Locais de Desenvolvimento da Maricultura são "instrumentos de planejamento participativo para a identificação de áreas propicias à delimitação dos parques aquicolas marinhos e estuarinos bem como das faixas ou áreas de preferência para comunidades tradicionais, com o objetivo de promover o desenvolvimento sustentável da maricultura em águas de dominio da União".

Essa definição indica que a elaboração dos PLDMs deve ocorrer de forma participativa e integrada, com o objetivo de avaliar o potencial da zona costeira para maricultura e subsidiar o processo de delimitaçáo das unidades de mapeamento aquícola. Trata-se de um instrumento técnicocientífico de apoio ao MPA no processo de planejamento dos parques aquícolas e das áreas de preferência.

Nessa instrução também estão descritos os aspectos prioritários no processo de elaboração dos planos, com destaque para caracterização ambiental dos domínios espaciais escolhidos, identificação de conflitos com outras atividades, prevenção de impactos decorrentes de atividades localizadas em terra e participação comunitária e institucional. Além disso, são apresentados alguns critérios que devem ser observados, entre os quais a compatibilização com outras políticas públicas, com destaque para os planos de gerenciamento costeiro e seus instrumentos: "No caso da existência de Zoneamento Ecológico Econômico Costeiro, este deverá servir como instrumento básico para a elaboração do PLDM"'.

Em seu anexo II, a Instrução Normativa 17/2005 traz um roteiro para elaboração dos planos, com configuração parecida com a de um Relatório de Impacto Ambiental (Rima). Esse roteiro foi substituído pelo anexo I da IN 11/2008, que passou a chamar-se Termo de referência para elaboração do PLDM, que, entre outras modificaçóes, passou a exigir o uso de Sistema de Informaçóes Geográficas como ferramenta de gestão.

\subsection{ZEEC e PGZC}

O ZEEC é um instrumento de ordenamento territorial, monitoramento, licenciamento e fiscalização que opera em consonância com as diretrizes da Política Nacional de Gerenciamento Costeiro. Deve ser elaborado de forma participativa e estabelecer diretrizes quanto aos usos proibidos, permitidos ou estimulados tanto em terra quanto no mar. No zoneamento de Santa Catarina foram definidas cinco zonas-tipo para usos específicos em área terrestre e nove para áreas marinhas (SPG, 2010b). Em relação à maricultura, há uma zona de manejo marinho (ZMMa) específica para a atividade, definida como "zona que apresenta estágios variados de qualidade ambiental, com potencial para implantação ou com parques aquicolas estabelecidos". As ZMMa estão baseadas na distribuição dos parques aquícolas e representadas em mapas temáticos projetados para sofrerem revisôes periódicas em função da dinâmica natural e social da zona costeira. Em
Santa Catarina o ZEEC e o PGZC foram publicados em 2010, e os documentos e mapas estáo disponíveis na página da Secretaria de Estado do Planejamento ${ }^{1}$.

Na primeira versão do Plano Nacional de Gerenciamento Costeiro os planos de gestão dependiam do ZEEC, forçando uma hierarquia metodológica em relação à implementação. Após a revisão do Plano Nacional de Gerenciamento Costeiro e a publicaçáo da segunda versão, conhecida como PNGC II (CIRM, 1997), os planos de gestão passaram a compor um instrumento independente, porém integrado ao zoneamento, compreendendo "a formulação de um conjunto de açôes estratégicas e programáticas, articuladas e localizadas, elaboradas com a participação da sociedade, que visam orientar a execução do Gerenciamento Costeiro".

No PGZC-SC estão apresentadas propostas de ação com metas bem definidas, responsabilidade institucional, área de atuação, prazos, custo aproximado e fontes potenciais de recursos. Seus principais objetivos são ordenar as diferentes atividades e usos do território costeiro e marinho, promover o desenvolvimento socioeconômico sustentável e garantir a conservação dos recursos naturais (SPG, 2010c). Apesar de o plano possuir caráter social e conservacionista, uma vez que incentiva a participação pública no processo de gestão e promove açóes de conservação, preservaçáo, recuperaçáo e educação ambiental, na prática os resultados efetivos ainda não foram percebidos. $\mathrm{O}$ processo participativo ainda não é socialmente representativo, mantendo-se direcionado a atores com níveis mais altos de poder técnico, político e econômico. Com isso o processo decisório ainda não atende plenamente aos anseios de uma sociedade democrática, repetindo o caráter tecnocrático do processo de gestão. As ações propostas são repetitivas e, na maioria das vezes, não levam em consideração as peculiaridades regionais e locais, assim como as de natureza setorial das diversas atividades costeiras.

\subsection{Sistemas de Informaçóes Geográficas para a Participaçáo Pública (SIG-PP)}

As políticas públicas previamente apresentadas possuem em comum a exigência da participação na implementação de seus instrumentos e nos processos de tomada de decisão. Numa perspectiva mais ampla, a participação deve facilitar o exercício do poder de decisão das pessoas e promover a elevação dos níveis de autossuficiência (Tapia et al., 2007).

Em diversos campos de conhecimento a palavra "participação" vem sendo acompanhada por adjetivos ou outros termos que complementam seu significado ou direcionam sua aplicação para um objetivo específico. $\mathrm{O}$ uso de Sistemas de Informaçôes Geográficas como instrumento de apoio à decisão de forma participativa foi apresentado em 1987 no relatório Chorley Report ${ }^{2}$ através do reconhecimento de questôes não técnicas, gerenciais e institucionais para a aplicação efetiva de um SIG (Weiner et al., 2002).

\footnotetext{
1 - http://www.spg.sc.gov.br/zoneamento.php ou http://www.spg.sc.gov. br/planogestao.php

2 - Nome dado ao documento Handling Geographic Information publicado pelo Department of Environment da Inglaterra em 1987.
} 
Mello (2003) justifica o uso de SIGs como ferramenta de apoio à decisão com a participação pública pelo uso de gráficos e imagens que são didaticamente mais adequados que tabelas e dados numéricos, afirmando que "imagens ou mapas transmitem a informação de forma muito mais sucinta, senão melhor, que tabelas, documentos ou equaçôes matemáticas". O autor apresenta uma revisão sobre Sistemas de Informaçôes Geográficas para Participação Pública (SIG-PP) na qual aborda aspectos históricos, institucionais e conceituais, concluindo que a participação pública na formulação, implementação e avaliação de políticas públicas é fundamental. Para isso, o grande desafio na utilização de SIG-PP está no desenvolvimento metodológico para encontrar formas de estimular e favorecer a participaçáo dos cidadãos no processo de tomada de decisão.

Os SIGs-PP vêm sendo construídos e difundidos por consórcios e instituiçôes de pesquisa independentes como o National Center for Geographic Information and Analysis $\left(\mathrm{NCGIA}^{3}\right)$ e o International Research Group on Geographic Information and Multicriteria Decision Analysis (GIMDA ${ }^{4}$ ). Ambos se dedicam à pesquisa básica e aplicada em educação, tecnologias, análise multicritério e processos de tomada de decisão participativos, com base na informação espacial e em geotecnologias.

No Brasil, uma iniciativa de desenvolvimento metodológico para implementação de políticas públicas através de SIG-PP é o Projeto Maplan ${ }^{5}$ no estado do Ceará. O objetivo do projeto é "promover a inclusão e a participação de pessoas e comunidades na definição da sua própria trajetória de desenvolvimento local'. Os mapas utilizados nas reunióes de planejamento foram construídos com informações geradas pelos próprios residentes e serviram de base para "auxiliar na identificação de condicionantes e potencialidades nas comunidades do interior e para discutir sobre as metas de desenvolvimento das populaçôes".

O SIG-PP pode ser classificado como uma ferramenta metodológica de auxílio ao processo decisório. O planejamento do espaço geográfico, seja terrestre, seja marinho, passa por questóes de análise espacial que são mais facilmente resolvidas com uso de mapas e SIG. Da mesma forma, o processo participativo necessário para a legitimação e consolidaçáo dos resultados do planejamento deve estar instrumentalizado. Assim, o SIG-PP atende não só às questôes técnicas, mas também àquelas que envolvem geração de informaçôes espaciais, compreensão dessas informaçôes, análise e proposiçẫo. $\mathrm{O}$ trabalho de planejamento do espaço por mapas é fundamental tanto para o ZEEC e o PGZC quanto para os PLDMs. Com isso, o SIG-PP também subsidia a estruturação do Sigerco tanto através da tecnologia do SIG quanto dos dados e informaçóes.

\section{EVOLUÇĀO DO GERENCIAMENTO COSTEIRO E ORDENAMENTO DA MARICULTURA EM SANTA CATARINA}

A cronologia de um processo de gestão focando uma política pública constitui-se em um interessante instrumento para o seu entendimento. Alguns marcos na gestão costeira e aquícola de Santa Catarina foram fundamentais para entender a realidade atual (Figura 4). Apesar de terem iniciado praticamente ao mesmo tempo, não há registros de uma integração significativa de ações ao longo do período considerado. Segundo o Gerco-SC, o Programa Estadual de Gerenciamento Costeiro teve início em 1987, um ano antes das primeiras açôes documentadas de assistência técnica e extensão rural voltadas para o cultivo de moluscos marinhos (Oliveira Neto, 2005). Esse fato indica que as primeiras iniciativas de gestão costeira e maricultura foram contemporâneas, porém com objetivos diferentes, sendo a primeira de natureza técnica, legal e institucional, e a segunda caracteristicamente produtiva. Apesar das diferenças, para que se estabelecessem como política pública ou atividade econômica foram necessários estudos específicos sobre a zona costeira catarinense.

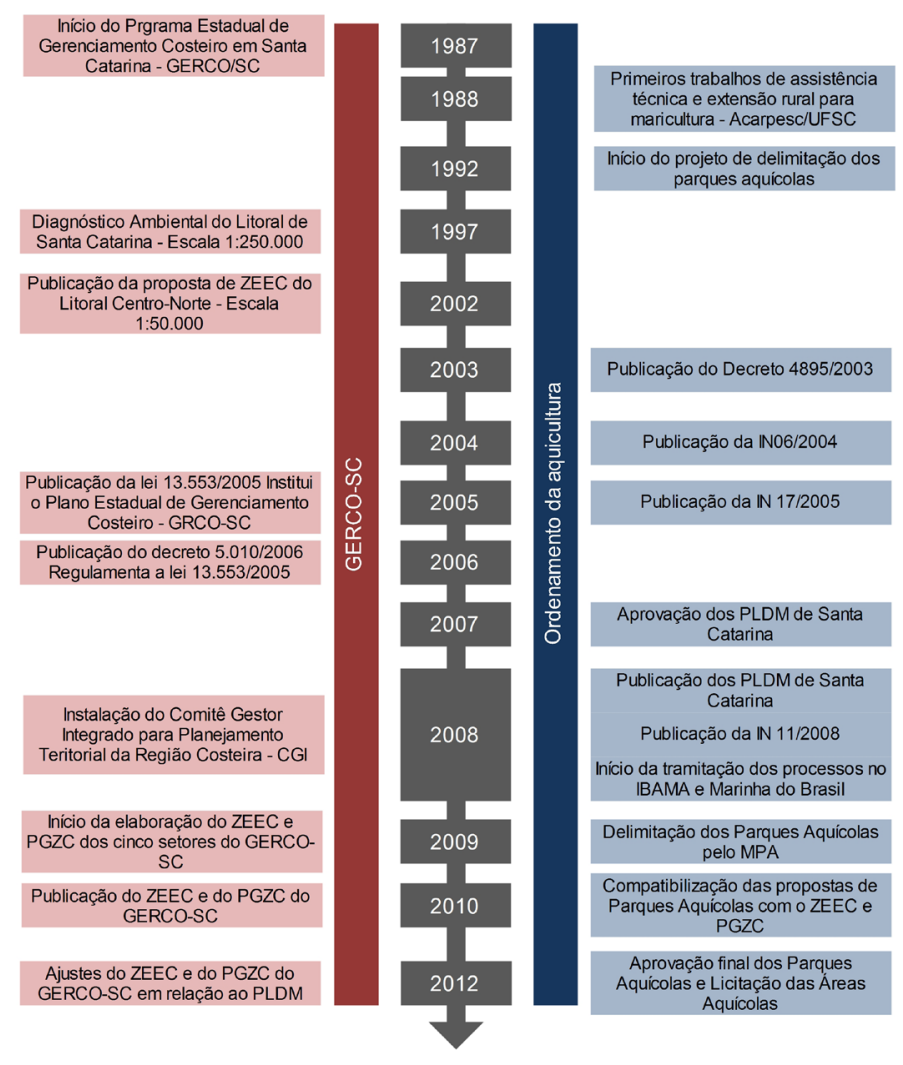

Figura 4. Cronologia dos principais marcos do Gerco-SC e do PLDM em Santa Catarina.

Figure 4. Chronology of the major landmarks of Gerco-SC and PLDM in Santa Catarina.

3 - http://www.ncgia.ucsb.edu/

4 - http://publish.uwo.ca/-jmalczew/gimda/

5 - http://projetomaplan.com/category/education/ 
A década de 1990 foi marcada por diagnósticos e levantamentos pelo Gerco-SC e pesquisa básica e aplicada sobre maricultura pela Empresa de Pesquisa Agropecuária e Extensão Rural de Santa Catarina (Epagri), Universidade Federal de Santa Catarina (UFSC) e Universidade do Vale do Itajaí (Univali).

Em 1997 foi publicado o Diagnóstico Ambiental do Litoral de Santa Catarina, um estudo coordenado pela então Secretaria do Desenvolvimento Econômico de Integração ao Mercosul sobre o uso e a ocupaçáo do litoral do Estado em escala 1:250.000. Foi a primeira iniciativa do Gerco-SC de integrar informaçóes sobre a zona costeira para fins de gestáo. Nesse mesmo período as pesquisas em relação à maricultura estiveram focadas em técnicas de cultivo, avaliação do potencial de produção do litoral catarinense e biologia, fisiologia e adaptaçáo de espécies com interesse comercial. Os primeiros resultados foram publicados em relatórios técnicos institucionais (Meyer, 1990; Costa et al., 1998; Rosa et al., 1998) e eventos científicos (Ferreira \& Magalhães, 1995; Guzenski \& Poli, 1996; Oliveira Neto \& Costa, 2000), com pouca divulgação científica em periódicos especializados (Freitas et al., 1996). Apesar dessas iniciativas, não foram encontrados registros explícitos de trabalhos integrados de gestão costeira e maricultura.

O diagnóstico realizado pelo Gerco-SC não aprofundou o tema maricultura com base nas pesquisas iniciadas, nem essas se ativeram aos instrumentos de gestão costeira que surgiam no âmbito das políticas públicas. A primeira proposta de ZEEC foi para o litoral Centro-Norte do estado de Santa Catarina, publicada pelo MMA e pela Secretaria do Estado do Desenvolvimento Urbano e Meio Ambiente de Santa Catarina (SDM) em 2002 (MMA, 2002). Foi o primeiro setor do Gerco-SC a ter um zoneamento com respectivos planos de gestáo elaborados de forma participativa e integrada, fortalecidos pela adoção do método de Gerenciamento Costeiro Integrado proposto por Polette (1997) e construídos diretamente com os municípios costeiros e com amplo envolvimento da sociedade local em um processo de governança. A proposta para zoneamento marinho foi pioneira tanto no Estado quanto em nível nacional, e as informaçóes geradas foram armazenadas e disponibilizadas no Sistema de Informaçōes Geográficas em Gerenciamento Costeiro (Sigerco), mas sem a abrangência necessária em relação à disponibilização de dados e informações para a sociedade.

Nessa época também houve a primeira iniciativa de ordenamentoda mariculturaemSantaCatarina, numaparceria entre a Epagri e o Instituto Brasileiro de Meio Ambiente e Recursos Naturais (Ibama). Os resultados foram publicados no Diagnóstico do Cultivo de Moluscos em Santa Catarina (Oliveira Neto, 2005). Com base em critérios técnicos como abrigo de ventos e correntes, profundidades superiores a $1,5 \mathrm{~m}$, afastamento de rotas tradicionais de embarcaçóes, fundeadouros, áreas de pesca tradicional, locais utilizados para atividades de turismo e lazer e desembocaduras de rios, foram utilizadas cartas náuticas para delimitar 155 parques aquícolas (1.213,35ha) e 719 áreas aquícolas (563,96ha) (Figura 5). Assim surgiram os conceitos institucionalizados no Decreto Federal 4.895, de 2003.

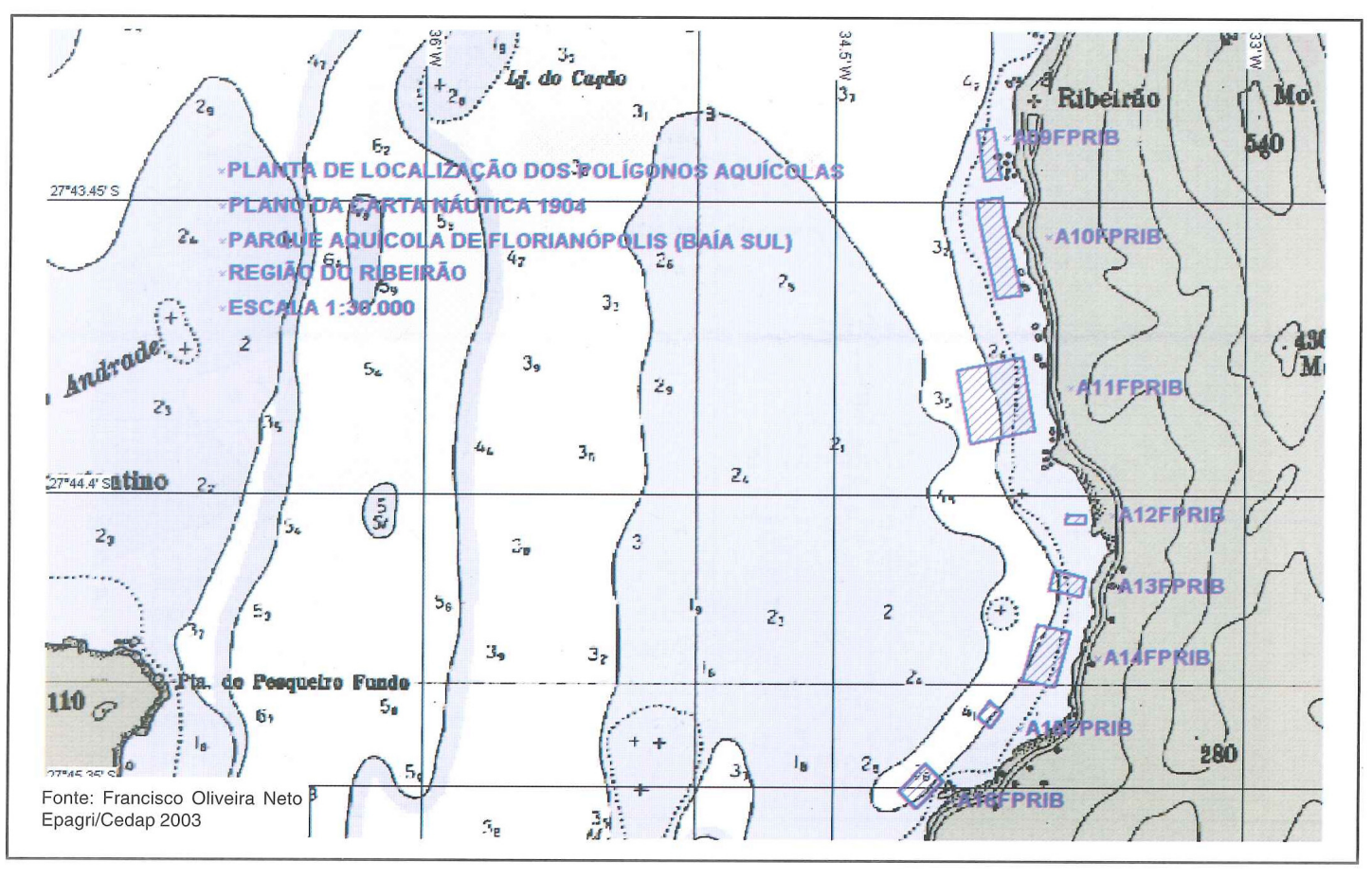

Figura 5. Delimitação de parques aquícolas em Santa Catarina: Exemplo aplicado à localidade do Ribeirão da Ilha, em Florianópolis. Fonte: Oliveira Neto (2005).

Figure 5. Delimitation of aquaculture areas in Santa Catarina: Example applied to the location of Ribeirão da Ilha, in Florianópolis. Source: Oliveira Neto (2005). 
No Brasil, em termos operacionais, foi uma das primeiras aplicaçóes de análise espacial adotada no processo de seleção de áreas para maricultura com foco na gestáo da atividade. Apesar de não ter sido implementado nenhum modelo em SIG, os critérios de avaliaçâo foram analisados em campo e visualmente sobre cartas náuticas, favorecendo a delimitação dos parques aquícolas. Esse processo foi fundamental para consolidar os parques aquícolas e as áreas aquícolas como unidades de mapeamento, essenciais ao ordenamento e gestão do espaço aquático.

De 2000 a 2005 o processo amadureceu considerando tanto o Gerco-SC quanto a maricultura, porém ainda de forma isolada e pouco integrada. Os aspectos levantados a respeito da maricultura e sua relaçáo socioeconômica, espacial e ambiental com outras atividades mantiveram-se carentes de dados importantes para definição de políticas setoriais. No relatório do ZEEC (MMA, 2002) destacou-se a importância da maricultura como atividade econômica e a necessidade de informar os maricultores e pescadores artesanais que iniciavam na atividade sobre "a real situação da qualidade de água e da necessidade de observar e adotar as normas sanitárias vigentes durante o cultivo e processamento dos moluscos". Contudo, não se podia contar com dados que sustentassem técnica e cientificamente um real risco à atividade, apesar do aumento significativo no número de publicaçóes em comparação à década de 90 (Curtius et al., 2003; Suplicy, 2003; Suplicy et al., 2003; Ferreira et al., 2004; Maccacchero et al., 2005; Albuquerque \& Ferreira, 2006). Assim foram levantadas suspeitas sobre condiçôes ambientais adversas e as propostas focaram ações de fiscalização, monitoramento e ordenamento.

Nesse período a atividade de maricultura atingiu seu ápice produtivo, tanto de ostras quanto de mexilhóes, e começou a apresentar sinais de estagnação (Epagri, 2010). Os conflitos com outras atividades como turismo, urbanização, navegação e pesca intensificaram-se e o setor passou a buscar estratégias de ordenamento (Oliveira Neto, 2005), mas ainda com pouca integração com o Gerco-SC.

Em 2005 foi instituído o Gerco-SC, pela Lei 13.553/2005, regulamentada pelo Decreto Estadual 5.010/2006. Também em 2005 a Seap lançou o Programa Nacional de Aquicultura e Pesca (Seap, 2005). Santa Catarina foi o estado pioneiro na sua implementação no Brasil. A elaboração dos PLDMs exigiu o desenvolvimento de uma metodologia que atendesse às diretrizes impostas pela legislação, de acordo com a realidade do país ao volume e à qualidade dos dados existentes sobre a zona costeira (Novaes et al., 2010).

Vianna et al. (2007) publicaram a metodologia de avaliação de potencial aquícola adotada em Santa Catarina e aplicada na etapa de análise de preparação dos mapas temáticos dos PLDMs. O trabalho foi feito utilizando técnicas de SIG-PP e os resultados apresentados em cartas-imagem de alta resolução e mapas temáticos, contendo informaçóes sobre o potencial aquícola do litoral, áreas aquícolas já implementadas, batimetria, legislação ambiental, unidades de conservação e uso da zona costeira e marinha. Esse material foi disponibilizado também em formato compatível com o Google Earth para facilitar o uso nas reuniôes setoriais e audiências públicas.
Nas reunióes setoriais participaram apenas técnicos, instituiçôes e pessoas diretamente ligadas à maricultura. $\mathrm{O}$ objetivo foi identificar os anseios e as necessidades do setor e elaborar uma proposta de distribuiçáo dos parques aquícolas para ser discutida posteriormente com os demais setores atuantes na zona costeira. $\mathrm{O}$ material gerado nas reunióes foi utilizado em 28 audiências públicas durante as quais foram apresentadas e discutidas as propostas de distribuição dos parques aquícolas em Santa Catarina.

As audiências foram coordenadas pela Seap e serviram para debater as necessidades e os anseios do setor produtivo aquícola com os demais setores atuantes na zona costeira. Após duas rodadas de audiências públicas em 14 localidades, os PLDMs dos municípios de Santa Catarina foram aprovados pelo comitê estadual e pela Seap, sendo publicados em 2008 (Seap, 2008). Após a publicação dos planos de Santa Catarina, a Seap publicou a IN 11/2008 com o "Termo de referência para elaboração do PLDM". Assim, todo o processo de planejamento dos parques aquícolas de Santa Catarina, desde as primeiras iniciativas em 1992 até a finalização dos PLDMs em 2008, levou 16 anos e serviu de modelo para as normativas de execução dos planos no Brasil.

Esse período deve ser analisado em dois momentos distintos: o primeiro, de 1992 a 2005, quando a zona costeira catarinense foi ocupada pela maricultura sem uso dos instrumentos normativos de ordenamento do espaço marinho, seguindo critérios definidos pelos próprios produtores em parceria com as instituiçóes que, à época, iniciaram os trabalhos de pesquisa, extensão e fomento à atividade.

A partir de 2005 os parques aquícolas foram propostos em um processo participativo setorial, conduzido pelas políticas públicas aquícolas constituídas. Com a publicação dos PLDMs em 2008, a Seap passou a contar com um instrumento legal, fundamentado técnica e cientificamente e representativo da demanda setorial aquícola por espaços de produção no litoral. Foi com essas informações que deu início à tramitação dos processos dos parques aquícolas no Ibama e na Marinha do Brasil, em conformidade com as normas instituídas pela IN 06/2004.

Paralelamente, ainda em 2008, foi instituído o Comitê Gestor Integrado do Gerco-SC, que, no ano seguinte, iniciou a implementação do PEGC com a elaboração do ZEEC e do PGZC dos cinco setores do litoral. Foi nesse período que as açóes do Gerco-SC e dos PLDMs convergiram de forma mais eficaz. Os processos dos parques aquícolas que tramitavam no Ibama e na Marinha foram também encaminhados ao Gerco-SC para serem integrados ao ZEEC, que passou a ser o instrumento adotado por todas as instituiçôes no planejamento do espaço geográfico marinho. Em 2009 a Seap obteve status de ministério e passou a chamar-se Ministério da Pesca e Aquicultura.

Em 2010 o Gerco-SC organizou 20 reunióes técnicas ao longo de todo o litoral de Santa Catarina para elaborar o zoneamento e discutir o enquadramento das cinco zonas. Nesse processo também foram adotadas técnicas de SIGPP (Figura 6) e participaram, entre outros atores, o MPA, a Marinha do Brasil e a Epagri.

O trabalho do comitê gestor durou quase dois anos e em 

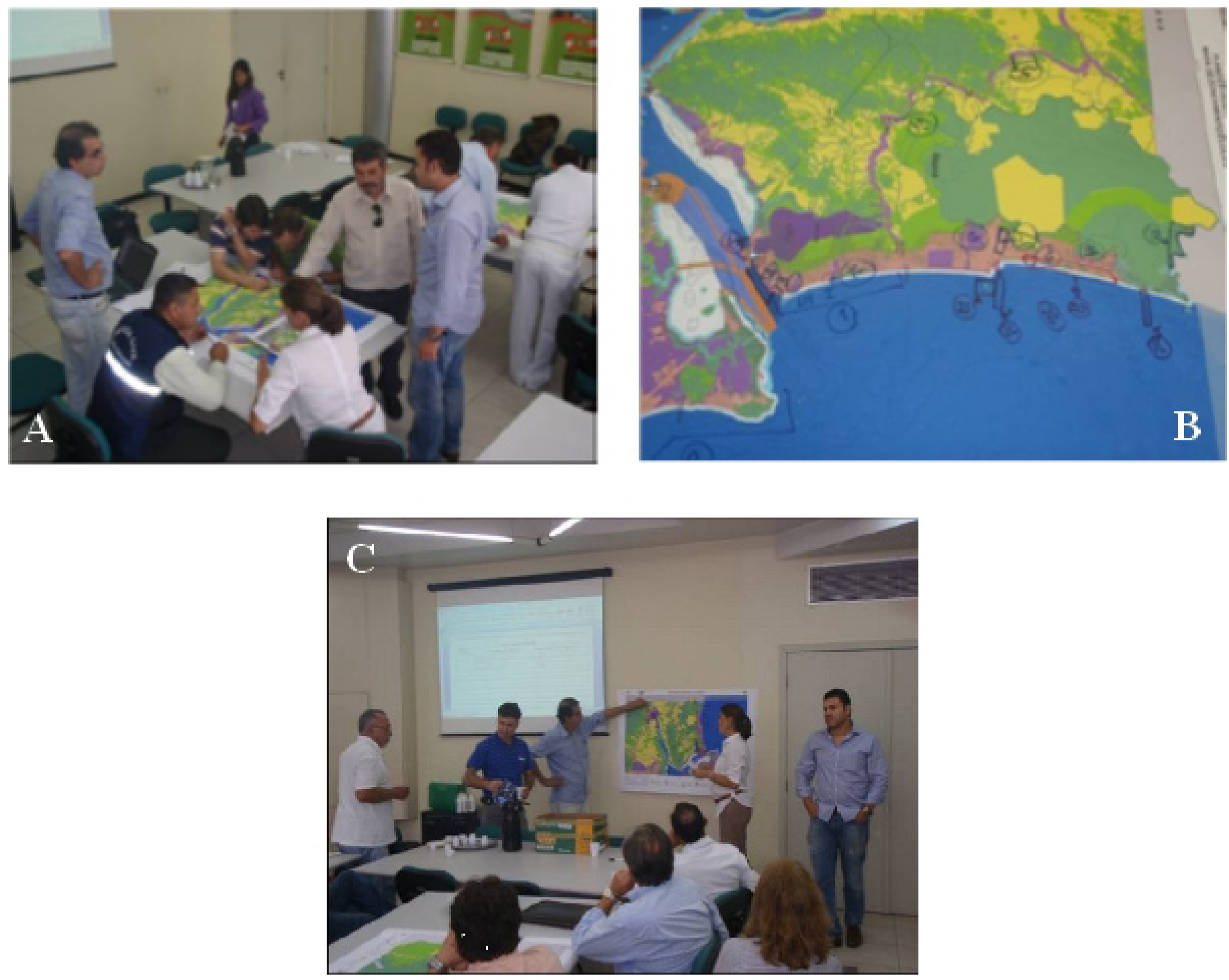

Figura 6. Aplicação da metodologia de SIG-PP no Gerco-SC: (A) Grupos de trabalho do ZEEC; (B) Propostas de zoneamento sendo trabalhada em mapa; (C) Apresentação e discussão das propostas pelos grupos de trabalho. Fonte: SPG (2010b).

Figure 6. Application of SIG-PP methodology in Gerco-SC: (A) ZEEC work groups; (B) zoning proposals being crafted on maps; (C) presentation and discussion of the proposals by the work groups. Source: SPG (2010b).

dezembro de 2010 os relatórios e mapas foram publicados pela Secretaria de Estado do Planejamento (SPG ${ }^{6}$ ) Atualmente, estão sendo feito ajustes no ZEEC em relação à distribuição dos parques aquícolas. Segundo publicado no comunicado de abril de 2011 do Gerco-SC, "Foram analisados os Planos Locais de Desenvolvimento da Maricultura (PLDM), resultando numa primeira proposta de zoneamento dos Parques Aquicolas a ser confirmada através de acordos posteriores entre órgãos públicos e comunidades envolvidas, sendo ainda, estes acordos, ratificados pelos executivos municipais".

\subsection{Evoluçáo das propostas dos parques aquícolas}

A Figura 7 ilustra a evolução das propostas dos parques aquícolas em relação ao número de parques e à área a ser

6 - http://www.spg.sc.gov.br/zoneamento.php ocupada. As alteraçóes ocorreram em função de mudanças de desenho, supressão, substituição, inserção e agrupamento de parques. A primeira proposta elaborada em 2007 foi técnica e baseada em critérios utilizados para avaliar o potencial da zona costeira catarinense para implementação dos parques aquícolas. Ela foi a base das discussóes para elaboração dos PLDMs, com 157 parques aquícolas ocupando uma área de 1.830 hectares.

A proposta resultante dos PLDMs, elaborada pelo setor aquícola catarinense durante as reuniôes técnicas e audiências públicas e publicada em 2008, foi ampliada para 178 parques aquícolas, que ocupariam uma área de 2.386,2 hectares. Em 2009 o MPA fez novas alteraçóes e apresentou uma proposta oficial ao Ibama, à Marinha do Brasil, à ANA e ao GercoSC. Durante o ano de 2010 foram feitas reunióes técnicas organizadas pelo Gerco-SC onde foram sugeridas alteraçóes significativas tanto no número quanto na área total dos parques aquícolas, para que se adequassem ao ZEEC. 
Com o objetivo de reduzir o número de processos dos parques aquícolas necessários para avaliação das instituiçôes listadas na IN 06/2004, o MPA agrupou os 159 parques aquícolas acordados com o Gerco ao final de 2010, em 27 parques. Esse agrupamento ocorreu considerando-se as áreas de preferência previstas no PLDM, ou seja, todos os parques contidos em uma área de preferência foram agrupados pelo somatório de suas áreas. Assim, tanto a distribuição espacial quanto a área total foram mantidas, mas o número de processos reduzido significativamente. A proposta hoje avaliada e parcialmente aprovada conta com 27 parques e uma área total de 1.736,5 hectares, bem próxima aos 1.830,7 hectares propostos tecnicamente na primeira versão.

A proximidade entre os valores de área da primeira proposta em 2007 e daquela que está sendo aprovada demonstra a importância do processo participativo. $\mathrm{O}$ incremento de mais de 500 hectares sobre a proposta técnica observado no ano de 2008 indica a existência de outros critérios originários do setor aquícola e com influência significativa no processo decisório. O resultado do PLDM parece ser legitimo em relação aos anseios daquele setor, porém não condizem com a expectativa dos demais setores que atuam na zona costeira.

A manutençáo de 2.366,8 hectares pelo MPA na proposta de 2009 também é legítima, considerando que é a instituição representante da atividade, porém tampouco reflete uma posição democrática. Ao passar pela avaliação das demais instituiçóes através do Gerco-SC, a proposta atual está mais próxima de um consenso multissetorial, o que aumenta a segurança sobre sua legitimidade como necessidade atual. $\mathrm{O}$ fato de ser quantitativamente semelhante, em área, à proposta técnica de 2007 sugere uma evolução também no processo cognitivo dos atores, pois a negociação não ocorreu apenas por pressóes setoriais, mas também pelos argumentos técnico-científicos.

Esses argumentos refletem-se também na distribuição espacial dos parques aquícolas, que pode ser mais bem avaliada por meio do SIG. Assim, a importância do SIG-PP se justifica pela capacidade de compatibilizar um instrumento de análise espacial com um processo de tomada de decisão participativo.

Apesar da proximidade entre os valores das áreas das duas propostas, apenas uma avaliação espacial foi capaz de auxiliar na identificação das diferenças. Na região de Palhoça (Figura 8A), por exemplo, um parque aquícola planejado em 2007 foi suprimido enquanto dois novos foram criados mais ao sul, compensando a perda de área com uma alteraçáo espacial. Para essa alteração foram considerados, além dos critérios técnicos e das informaçóes geradas em 2007/2008, as necessidades, os conhecimentos e os anseios dos demais setores envolvidos. $\mathrm{O}$ mesmo pode ser observado na costa norte de Governador Celso Ramos, onde se percebe a supressáo de três pequenos parques aquícolas, compensados pela ampliaçấo de outro bem próximo, a oeste deles (Figura 8B).

\section{COMPATIBILIZAÇÁO ENTRE GERENCIAMENTO COSTEIRO E ORDENAMENTO DA MARICULTURA EM SANTA CATARINA}

A cronologia do processo de gestão costeira e aquícola em Santa Catarina indica que os instrumentos legalmente instituídos pelos ministérios do Meio Ambiente e da Pesca e Aquicultura se mostraram tecnicamente eficientes, porém foram implementados de forma tecnocrática, burocrática e pouco integrada: os PLDMs como planos setoriais auxiliares, o ZEEC como instrumento de planejamento do espaço geográfico costeiro e o PGZC como direcionador de açôes.

A legislação que normatiza essas políticas é clara sobre suas funçôes e relações. Os PLDMs são um instrumento de auxílio ao planejamento da maricultura que fornece informaçōes necessárias para que o setor se organize e

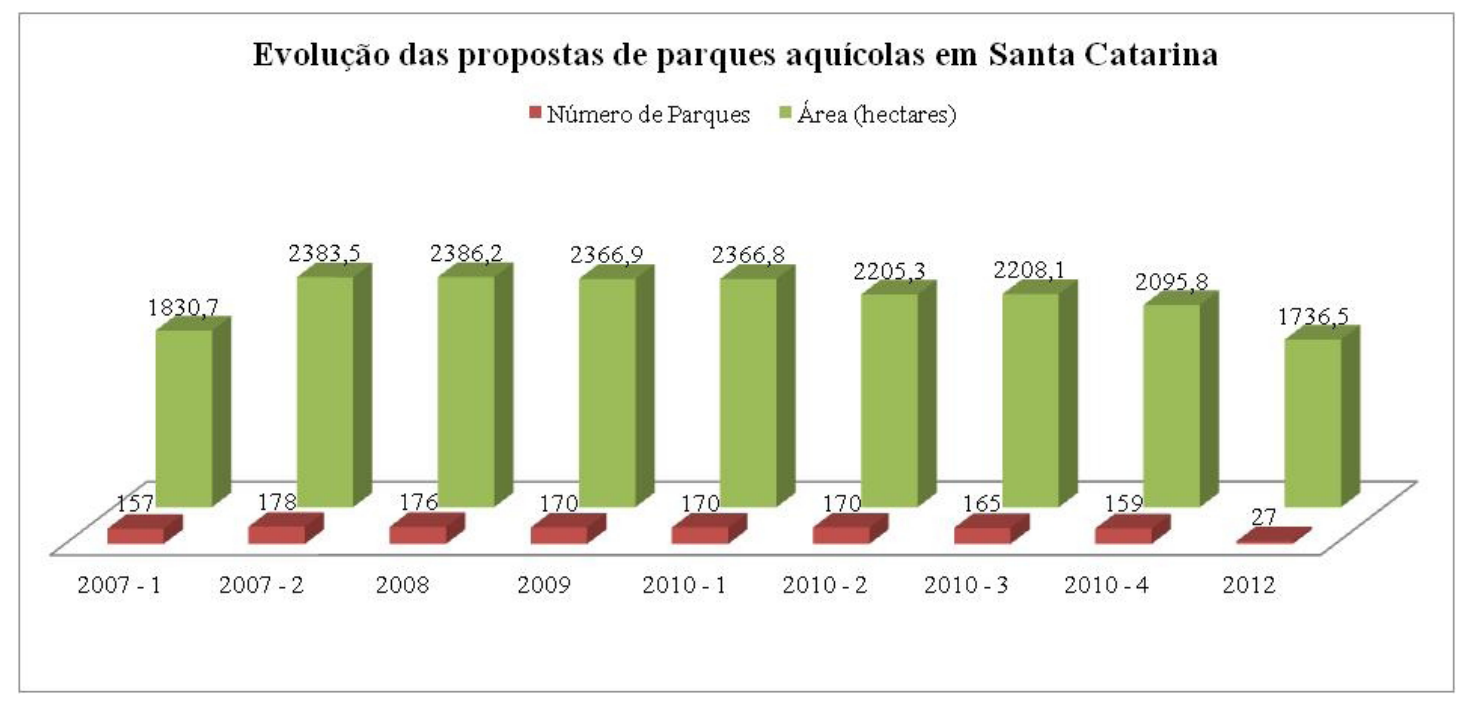

Figura 7. Evolução das propostas dos parques aquícolas em Santa Catarina em relação à quantidade e área (hectares) a ser ocupada

Figure 7. Evolution of the proposals of the aquaculture areas in Santa Catarina in relation to the number and area (hectares) to be occupied. 

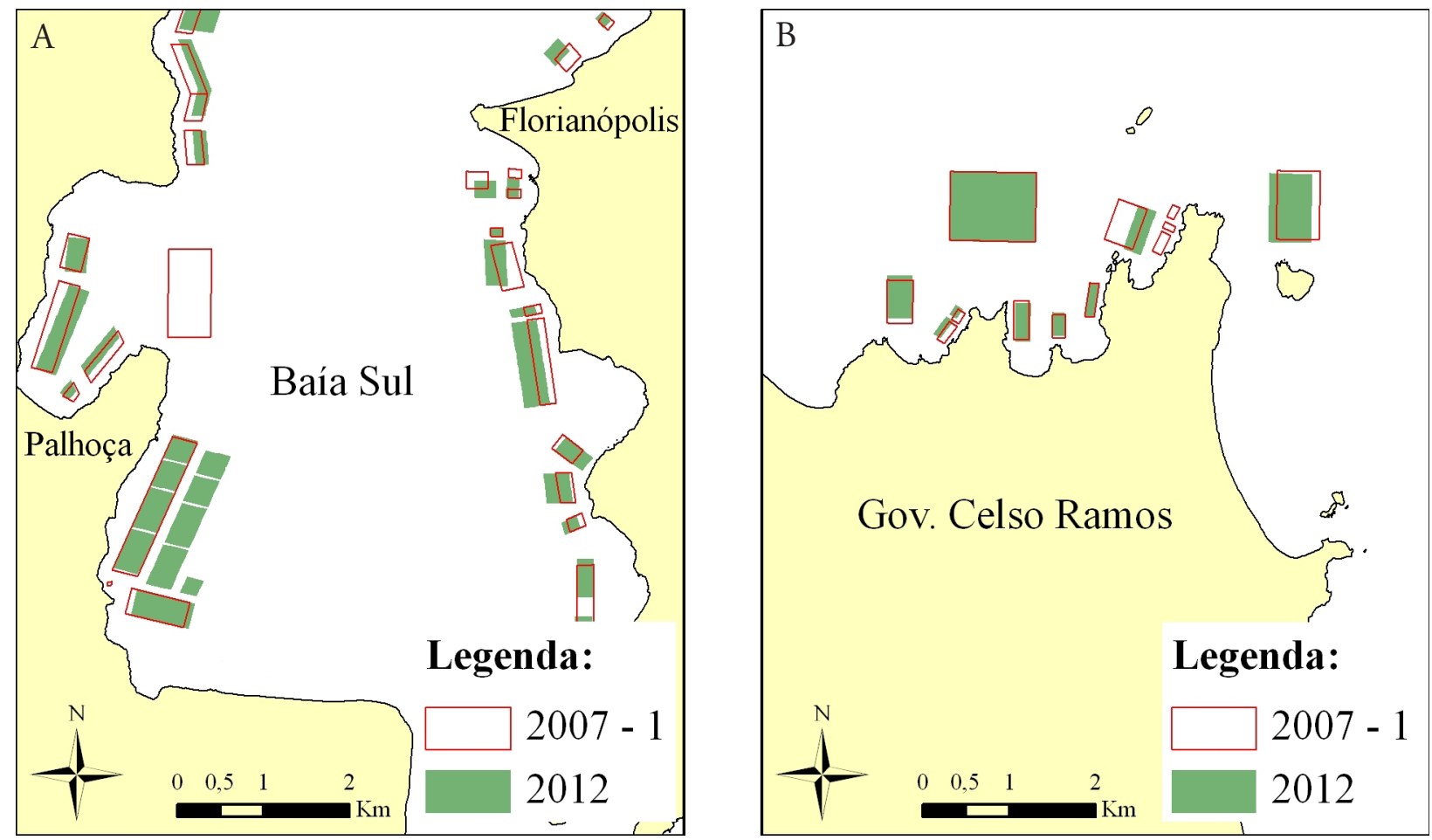

Figura 8. Evolução das propostas dos parques aquícolas em Santa Catarina em relação à disposição espacial de 2007 para 2008: (A) Florianópolis e Palhoça, na Baía Sul; (B) norte de Governador Celso Ramos.

Figure 8. Evolution of the proposals of the aquaculture areas in Santa Catarina in relation to spatial layout from 2007 to 2008 : (A) Florianópolis and Palhoça, in South Bay; (B) north of Governador Celso Ramos.

proponha cenários de uso e ocupação da zona costeira com base em critérios técnicos, científicos e legais. O ZEEC é o instrumento integrador dos anseios multissetoriais pelo uso do espaço geográfico costeiro através de consenso e com capacidade adaptativa para acompanhar a dinâmica das atividades antrópicas e naturais que ali ocorrem. O PGZC, por sua vez, apresenta de forma detalhada as ações necessárias para que se cumpram os objetivos da gestão.

Nesse contexto, os PLDMs podem ser elaborados independentemente dos instrumentos do Gerco ou paralelamente a eles, mas após sua finalização devem ser implementados através deles. Isso significa que o setor aquícola possui um instrumento próprio de planejamento, mas que deve estar de acordo com uma política pública mais abrangente e de integração multissetorial e interinstitucional. Os parques aquícolas propostos pelo MPA devem ser aprovados não apenas no âmbito setorial, com reuniōes técnicas e audiências públicas direcionadas ao setor aquícola, mas em um fórum de discussão mais amplo, que permita resolver conflitos de uso do espaço com outras atividades.

O processo participativo de elaboração dos PLDMs em Santa Catarina ocorreu anteriormente ao do ZEEC. Com isso o MPA buscou, com a realizaçáo de 28 audiências públicas, ampliar a discussão acerca da delimitação dos parques aquícolas com atores importantes de outros setores, porém sem a abrangência exigida por um processo como o de elaboraçáo do ZEEC. Assim, a primeira proposta de Parques Aquícolas em Santa Catarina, aprovada no âmbito do MPA e publicada em 2008, teve que integrar-se ao ZEEC a partir de 2010. Esse processo seria mais eficiente se as reunióes técnicas e audiências públicas fossem planejadas de forma integrada e os PLDMs definidos setorialmente para ser apresentados e discutidos publicamente através do ZEEC no Gerco-SC.

O Estado ainda não possui estrutura compatível com as necessidades logísticas, técnicas e metodológicas para conduzir integralmente o processo de gestão da zona costeira. Esse fato já foi identificado por autores há quase dez anos (Asmus et al., 2004; Polette et al., 2004) e continua sem solução. A gestão costeira náo tem sido prioridade política para o governo estadual desde o início das açôes, em 1987. Apesar de ter um agente institucional específico para esse fim, o programa de gestão costeira tem passado por migraçôes periódicas entre Secretarias de Estado dificultando, assim, a manutenção de uma equipe dedicada e qualificada para conduzir um processo complexo, de natureza interdisciplinar e com exigência de recursos humanos e infraestrutura qualificada. As medidas adotadas para minimizar tais dificuldades por parte do Estado estáo hoje atreladas a parcerias e contratos com empresas de consultoria que executam açóes pontuais e momentâneas, incapazes de abranger a dinâmica necessária para atingir os reais objetivos propostos no próprio processo pré-licitatório. A gestão costeira tem como característica peculiar ser de responsabilidade principal do Estado, conduzida por um processo de governança com a participaçáo e o comprometimento efetivo da sociedade. 


\section{CONSIDERAÇÓES FINAIS E PERSPECTIVAS}

A experiência de Santa Catarina demonstrou que a integração dos PLDMs com o Gerco-SC através do ZEEC e do PGZC é um caminho interessante para a gestão aquícola. Assim, é possível atender às normas instituídas legalmente, integrar instituiçóes de diversos setores e promover um debate democrático sobre a gestão costeira. Segundo Asmus et al. (2004), a sustentabilidade política e socioeconômica nos processos decisórios só é possível com a participação e o envolvimento integral das forças ativas da sociedade. Apesar de os autores identificarem à época uma fragilidade em relação à participação da sociedade nas açóes de gerenciamento costeiro, na elaboraçáo dos PLDMs essa participação, mesmo setorial, foi efetiva e legítima. $O$ processo participativo no zoneamento dos parques aquícolas favoreceu o aumento de poder das associaçóes de maricultores e da Epagri no processo decisório, assim como subsidiou o ordenamento do espaço marinho.

Isso demonstra um avanço em comparação ao observado tanto por Polette et al. (2004) quanto por Asmus et al. (op. cit.) em relação ao desinteresse da população e ao baixo envolvimento de instituições de pesquisa e extensão. Por outro lado, no âmbito do Gerco-SC, o fortalecimento das tomadas de decisão tendo como base a sociedade costeira e as instituiçôes de pesquisa ainda tem sido incipiente e corrobora para manter aspectos de natureza político-institucional e tecnocrática de gestão sem visão de longo prazo, assim como da própria manutenção do status quo de setores que não possuem interesse em mudanças que exijam novas posturas ante elementos da sustentabilidade.
Oestado de Santa Catarina demonstrou estar tecnicamente capacitado para promover mudanças no processo de gestão costeira, porém ainda são necessários ajustes políticoinstitucionais para que os papéis dos atores envolvidos se tornem mais contundentes e as açóes necessárias para tais mudanças sejam articuladas de forma mais participativa e comprometida. Durante o processo do Gerco-SC houve mudanças político-administrativas que interromperam o processo algumas vezes. Deve ser destacado ainda que, se na época em que o PLDM foi elaborado o ZEEC já estivesse instituído, o MPA poderia ter contado com esse instrumento na elaboração dos seus planos. No entanto, também é importante salientar que a elaboração prévia dos planos permitiu utilizá-los como base para o ZEEC.

Em escala federal, para que o MPA possa exercer sua funçáo institucional sobre o ambiente marinho costeiro no que se refere à efetivação dos parques aquícolas e à licitação das áreas aquícolas, é necessário anuência do MMA, da Autoridade Marítima, do Ministério do Planejamento, Orçamento e Gestão e da ANA. Como o PNGC é uma política interministerial gerida pelo MMA, essa anuência pode ser data através do ZEEC e do PGZC desde que elaborados com participação efetiva das demais instituições envolvidas. Além disso, tanto o PNGC quando os PLDMs podem ser descentralizados e executados pelos estados e municípios, auxiliando o MPA em suas ações.

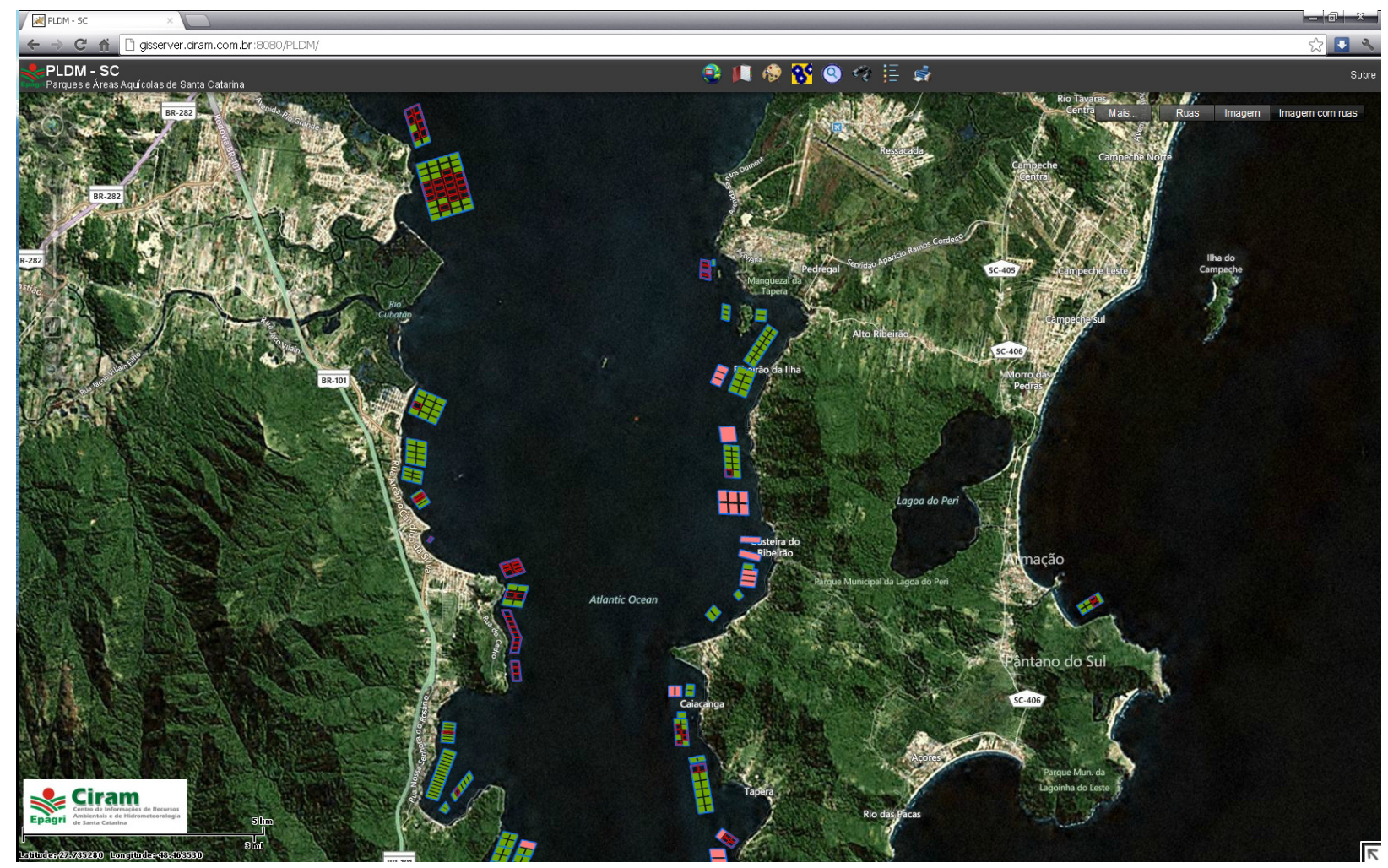

Figura 9. Sistema de gestão dos parques e das áreas aquícolas de Santa Catarina. Fonte: http://ciram.epagri.sc.gov.br/sipldm/ Figure 9. Management system of parks and of aquaculture areas of Santa Catarina. Source: http://ciram.epagri.sc.gov.br/sipldm/ 


\subsection{Alguns avanços necessários}

Uma vez instituídos os PLDMs em conformidade com o ZEEC e o PGZC, é necessário avançar com os instrumentos de monitoramento e avaliação. A próxima etapa abrangerá a revisão do ZEEC e do PGZC e a implantação do Sistema de Monitoramento Ambiental da Zona Costeira (SMA-ZC) e dos Relatórios de Qualidade Ambiental da Zona Costeira (RQA-ZC) (SPG, 2010d). A avaliação se faz fundamental, uma vez que o Estado ainda não possui estrutura para conduzir o processo participativo de forma eficaz, o que compromete a sua integração com os demais atores sociais. Em relação a isso o programa estadual alinha-se ao federal, ambos ainda carentes quanto à avaliação, necessitando estabelecer metas e cenários prováveis e definir indicadores de avanço e sucesso (Asmus et al., 2004).

Para a maricultura esses instrumentos já estão sendo implantados. $\mathrm{O}$ monitoramento de alguns parques aquícolas propostos no PLDM vem sendo realizado pela Epagri desde 2007. Um exemplo é o controle higiênicosanitário de moluscos que pode ser acessado pelo Centro de Desenvolvimento em Aquicultura e Pesca $\left(\operatorname{Cedap}^{7}\right)$.

No âmbito da ciência e tecnologia como suporte ao gerenciamento costeiro, Asmus et al. (2004) destacaram que "os órgáos de gestão precisam desenvolver uma cultura e tecnologia referentes à implantação e utilização de sistemas de informaçóes georreferenciados". Uma forma de ampliar o alcance do SIG-PP é investir em sistemas de mapas via internet. Nesse sentido, Vianna \& Novaes (2011) apresentaram um método de geocodificação das unidades de mapeamento aquícola e um modelo de dados para um sistema de gestão de parques e áreas aquícolas com base na geocodificação política adotada no Brasil pelo Instituto Brasileiro de Geografia e Estatística (IBGE). Esse sistema foi testado por um serviço de mapas via internet (Figura 9) e, segundo os autores, está apto para realizar consultas e estatísticas espaciais sobre dados de maricultura por estado, município, unidade de mapeamento aquícola, processo de solicitação de áreas aquícolas e maricultor, além de estar preparado para atender às necessidades de dados e informaçóes para um sistema de rastreabilidade.

O estado de Santa Catarina, através da Epagri, vem desenvolvendo esse sistema para utilizá-lo na gestão dos parques e áreas aquícolas. Estão sendo agregados dados de monitoramento e ferramentas de análise para que seja possível identificar as áreas aquícolas que sofrem ação de floraçóes de algas tóxicas ou esgoto doméstico, em desconformidade com a legislação sanitária.

Tanto o monitoramento quando o sistema, apesar de estarem focados na maricultura, podem perfeitamente contribuir com o Sigerco, assim como ocorreu com os PLDMs para o ZEEC. Entretanto, para que isso possa se concretizar é fundamental a existência de uma efetiva vontade política e o desenvolvimento de estratégias administrativas que promovam uma maior integração interinstitucional.

Os instrumentos das políticas públicas de gestão costeira e aquícola no Brasil aqui apresentados mostraram-

7 - http://cedap.epagri.sc.gov.br se tecnicamente aplicáveis, mas para que se tornem mais eficientes no processo de gestão costeira é preciso que haja maior integração institucional, um processo participativo abrangente e transparente e mais eficácia administrativa do Estado. O ZEEC e os PLDMs devem ser elaborados concomitantemente e de forma integrada, e os atores envolvidos nesse processo, governamentais ou não, devem participar de forma efetiva de cada etapa para que não ocorra retrabalho no ordenamento do espaço costeiro. Tais instrumentos, uma vez implementados, devem ser dinâmicos, apoiados por programas de monitoramento que abordem indicadores sociais, econômicos, ambientais e de governança que favoreçam o acompanhamento das frequentes mudanças de uso e ocupação do solo e do mar na zona costeira.

\section{BIBLIOGRAFIA}

Albuquerque, M.C.P.; Ferreira, J.F. (2006) - Eficiência comparada do cultivo da vieira Nodipecten nodosus (Linnaeus, 1785) em diferentes densidades e profundidades. Biotemas (ISSN: 2175-7925), 19(2):27-35, Florianópolis, SC, Brasil. Disponível em http://periodicos.ufsc.br/index.php/biotemas/article/ view/21213/19179

Asmus, M.; Kitzmann, D.; Laydner, C.; Tagliani, C. R. A. (2004) - Gestão Costeira no Brasil: Instrumentos, Fragilidades e Potencialidades. Gestão Costeira Integrada (ISSN: 1677-4841) 5:52-57, Itajaí, SC, Brasil. texto disponível em http://www.praia.log.furg.br/ Publicacoes/2006/2006a.pdf

CIRM (1997) - Resolução no 005, de 03 de dezembro de 1997. Aprova o Plano Nacional de Gerenciamento Costeiro II - PNGC II. 9p., Comissão Interministerial para os Recursos do Mar, Ministério do Meio Ambiente, Brasília, DF, Brasil. Disponível em http://www.mma.gov.br/ estruturas/orla/_arquivos/pngc2.pdf.

Costa, S.W. da; Grumann, A.; Oliveira Neto, F.M. de; Rockzanski, M. (1998) - Cadeias produtivas do Estado de Santa Catarina: Aquicultura e pesca. Boletim técnico (ISSN 0100-7416), no97, 62p., Epagri - Empresa de Pesquisa Agropecuária e Extensão Rural de Santa Catarina, Florianópolis, SC, Brasil. http://cedap.epagri. sc.gov.br/index.php?option $=$ com_docman \& task $=$ doc_ download\&gid=382\&itemid $=173$

Curtius, A.; Seibert, E. I.; Fiedler, H.; Ferreira, J. F; Vieira, P. F. (2003) - Avaliando a contaminação por elementos traço em atividades de maricultura. Resultados parciais de estudos de caso realizados na Ilha de Santa Catarina, Brasil. Quimica Nova. 26(1):44-52. Disponível em http://www.scielo.br/pdf/qn/v26n1/14300.pdf

Epagri (2010) - Sintese informativa da Maricultura 2010.9p., Epagri - Empresa de Pesquisa Agropecuária e Extensão Rural de Santa Catarina, Cedap - Centro de Aquicultura e Pesca, Florianópolis, SC, Brasil. Disponível em http://cedap.epagri.sc.gov.br/index.php?option $=$ com_ docman\&task=doc_download\&gid=357\&Itemid=173

Fatma - Fundação do Meio Ambiente (2012) - Histórico da balneabilidade. Fatma - Fundação de Meio Ambiente de Santa Catarina, Florianópolis, SC, Brasil. http://www. fatma.sc.gov.br/laboratorio/dlg_balneabilidade2.php.

Ferreira, J.F.; Besen, K.; Wormsbecher, A.G.; Santos, R.F., (2006) - Physical-chemical parameters of seawater 
mollusc culture sites in Santa Catarina- Brazil. Journal of Coastal Research (ISSN 0749-0208), SI 39:1122-1126. Itajaí, SC, Brazil. Disponível em http://cerf-jcr.org/ images/stories/232_ferreira.pdf

Ferreira, J.F.; Magalhães, A.R.M. (1995) - Desenvolvimento do cultivo de mexilhöes em Santa Catarina (Sul do Brasil) - VI Congresso Latinoamenticano de Ciências del Mar, p.80, Mar del Plata. Argentina.

Freitas, M.; Ferreira, J.F.; Magalhães, A.R.M. (1996) Cultivated marine mussel grouth in southern Brazil. Journal of Medical and Applied Malacology (ISSN 1053-6388), 8(1):155-156, Proceedings of the Fourth International Congress on Medical and Applied Malacology, Santiago, Chile.

Guzenski, J.; Poli, R. (1996) - Comparação do crescimento de ostra-do-mangue, Crassostrea rhizophorae (Guilding, 1828), em diferentes ambientes. IX Simpósio Brasileiro de Aquicultura, Sete Lagoas, MG. Resumos. Associação Brasileira de Aquicultura - ABRAq, São Paulo, Brasil.

Maccacchero, G.B.; Guzensky, J.; Ferreira, J.F. (2005) - Allometric growth on mangrove oyster Crassostrea rhizophorae (Guilding, 1828), cultured in Southern Brazil. Revista Ciência Agronômica (ISSN 0045-6888), 36(3):400-403. Disponível em http://www.ccarevista. ufc.br/seer/index.php/ccarevista/article/view/239/234

Mello, L.F.D. (2003) - Sistemas de Informação Geográfica para a Participação Pública: Uma Metodologia em Construção. Anais do $3^{\circ}$ Encontro Nacional Sobre Migração, 10p., Campinas, SP, Brasil. Disponível em http://www.abep. nepo.unicamp.br/docs/eventos/transdisciplinar/amb_ FreiredeMello.pdf

Meyer, M.M. (1990) - Relatório técnico do projeto experimental de mexilhão Perna perna (Linne, 1958) no município de Palhoça, Enseada do Brito e custo de produção para projeto modular. Acarpesc - Associação de Crédito e Assistência Pesqueira de Santa Catarina, Florianópolis, SC, Brasil. Não Publicado.

MMA (2002) - Zoneamento Ecológico-Econômico Costeiro do Projeto Gerenciamento Costeiro Integrado nos Municipios da Peninsula de Porto Belo e Entorno, e da Foz dos Rios Camboriú e Itajai - SC. 161p., MMA - Ministério do Meio Ambiente, PNMA II - Programa Nacional do Meio Ambiente, SDM - Secretaria de Estado do Desenvolvimento urbano e Meio Ambiente, Itajaí, SC, Brasil. Disponível em http://www.sds.sc.gov. $\mathrm{br} /$ index.php?option $=$ com_docman $\&$ task $=\mathrm{doc}_{-}$ download\&gid $=36 \&$ itemid $=46 \&$ lang=

Novaes, A.L.T.; Vianna, L.F.; Santos, A.A. dos; Silva, F.M.; Souza, R.V.D. (2010) - Planos Locais de Desenvolvimento da Maricultura de Santa Catarina. Panorama da Aquicultura (ISSN: 1519-1141), 21:52-58, Laranjeiras, RJ, Brasil. Disponível em http://cedap.epagri. sc.gov.br/index.php?option=com_docman\&task $=$ doc_ download\&gid $=283 \&$ \&itemid $=173$

Oliveira Neto, F.M. (2005) - Diagnóstico do cultivo de moluscos em Santa Catarina. Florianópolis. Boletim técnico (ISSN 0100-7416), no 220, 67p., Epagri - Empresa de Pesquisa Agropecuária e Extensão Rural de Santa Catarina, Florianópolis, SC, Brasil. Disponível em http://cedap.epagri.sc.gov.br/index.php?option $=\mathrm{com}_{-}$ docman\&task=doc_download\&gid=345\&itemid $=173$

Oliveira Neto, F.M. de; Costa, S.W. (2000) - Cultivo experimental da vieira Nodipecten nodosus em diferentes ambientes do litoral de Santa Catarina. XI Simpósio Brasileiro de Aquicultura, Anais, Florianopolis, SC, Brasil. CD-ROM.

Olsen, S.; Lowry, K.; Tobey, J. (1999) - A manual for assessing progress in coastal management. 56p., University of Rhode Island, Coastal Resources Center, Narragansett, RI, U.S.A. Disponível em http://www.crc.uri.edu/download/ SEL_003F.PDF.

Polette, M. (1997) - Gerenciamento Costeiro Integrado: Proposta Metodológica para a Paisagem da Microbacia de Mariscal - Bombinhas (SC). 499p., Tese de Doutorado, Universidade Federal de São Carlos, São Carlos, SP, Brasil. Não Publicado.

Polette, M.; Rebouças, G.N.; Filardi, A.C.L.; Vieira, P.F. (2004) - Rumo à Gestão Integrada e Participativa de Zonas Costeiras no Brasil: Percepçóes da Comunidade Científica e do Terceiro Setor. Gestão Costeira Integrada (ISSN: 1677-4841) 5:43-48, Itajaí, SC, Brasil.

Polette, M.; Silva, L.P. (2003) - GESAMP, ICAM e PNGC - Análise comparativa entre as metodologias de gerenciamento costeiro integrado. Ciência e Cultura (ISSN 0009-6725), 55(4):27-31, Sociedade Brasileira para o Progresso da Ciência, Campinas, SP, Brasil. Brasil. http://cienciaecultura.bvs.br/pdf/cic/v55n4/a17v55n4. pdf

Rosa, R de C.C.; Ferreira, J.F.; Pereira, A.; Magalhães, A.R.M.; Oliveira Neto, F.M. de; Guzenski, J.; Antoniolli, M.A.; Rodrigues, P. de T.T.; Ogliari, R.A. (1998) - Biologia e cultivo de mexilhôes. 106p., Epagri / UFSC, Florianópolis, SC, Brasil. Não Publicado.

SEAP (2005) - Programa Nacional de Desenvolvimento da Maricultura em Águas da União. 44p., SEAP - Secretaria Especial de Aqüicultura e Pesca da Presidência da República, Ministério da Pesca e Aqüicultura, Brasília, DF, Brasil. Não Publicado.

SEAP (2008) - Planos Locais de Desenvolvimento da Maricultura de Santa Catarina. 318p., SEAP - Secretaria Especial de Aquicultura e Pesca, Ministério da Pesca e Aquicultura. Brasília, DF, Brasil. Não Publicado.

SPG - (2010d) - Programação da implantação dos demais instrumentos do Plano Estadual de Gerenciamento Costeiro: Estratégias e Propostas. 35p., SPG - Secretaria de Estado do Planejamento, Florianópolis, SC, Brasil. Disponível em http://www.spg.sc.gov.br/Desenvolvimento de Cidades/ Gerco/Demais Instrumentos - Estra e Prop - GERCO_ SC \%5BIm.pdf

SPG - Secretaria de Estado do Planejamento. (2010c) - Implantaçáo do Plano Estadual de Gerenciamento Costeiro. Fase 1: Plano de Gestão Regional. 49p., SPG Secretaria de Estado do Planejamento, Florianópolis, SC, Brasil. Disponível em http://www.spg.sc.gov.br/ Desenvolvimento de Cidades/Gerco/Planos de Gestao/ Plano Gestao Regional.pdf.

SPG (2010a) - Implantação do Plano Estadualde Gerenciamento Costeiro. Fase 1: Diagnóstico Sócio Ambiental - Setor Litoral Central. 525p., SPG - Secretaria de Estado do Planejamento, Florianópolis, SC, Brasil. Disponível em 
http://www.spg.sc.gov.br/Desenvolvimento de Cidades/ Gerco/Diagnostico Socio Ambiental/Gerco_Setor 3_site. pdf

SPG (2010b) - Implantação do Plano Estadual de Gerenciamento Costeiro. Fase 1: Zoneamento EcológicoEconômico Costeiro - Setor Litoral Central. 192p., SPG - Secretaria de Estado do Planejamento, Florianópolis, SC, Brasil. Disponível em http://www.spg.sc.gov.br/ Desenvolvimento de Cidades/Gerco/Zoneamento/ Relatorios/Relatorio_ZEEC_S2_I.pdf

Suplicy, F.M. (2003) - Modelling growth and population dynamics of the brown mussel Perna perna (L.) in suspended culture in Santa Catarina, Brazil. World Aquaculture 2003, Salvador / World Aquaculture 2003, Baton Rouge, World Aquaculture Society. 2:767-767.

Suplicy, F.M.; Schmitt, J.F.; Moltschaniwskyj, N.A.; Ferreira, J.F. (2003) - Modelling of filter-feeding behavior in the brown mussel Perna perna (L.) exposed to natural variations of seston availability in Santa Catarina, Brazil. Journal of Shellfish Research (ISSN: 0730-8000), 22(1):125-134, National Shellfisheries Association, Oxford, MD, U.S.A.

Tapia, M.; Brasington, A.; Lith, L.V. (2007) - Participation Guide: Involving Those Directly Affected in Health and Development Communication Programs. 40p., Health Communication Partnership based at the Johns Hopkins Bloomberg School of Public Health/Center for Communication Programs, Baltimore, MD, U.S.A. Disponível em http://www.jhuccp.org/hcp/pubs/tools/ participationguide.pdf
Vianna, L.F.; Francisco, C.N.; Figeiredo C.; Simão, D.S.; Bannwart, J.; Wasserman, J.; Scott, P.C.; Novaes, R.; Hamilton, S. (2007) - Geotecnologias aplicadas para ordenamento da maricultura no Brasil: Uma avaliação dos Planos Locais de Desenvolvimento da Maricultura - PLDM. XII COLACMAR - XII Congresso LatinoAmericano de Ciências do Mar, p.548, Florianópolis, SC, Brasil.

Vianna, L.F.; Novaes, A.L.T. (2011) - Geocodificação de unidades de mapeamento aquícola para um sistema de controle de produção e rastreabilidade em Santa Catarina, Brasil. Geografia (ISSN 0100-7912), 36:163-178, Rio Claro, SP, Brasil.

Weiner, D.; Harris, T.M.; Craig, W.J. (2002) - Community Participation and Geographical Information Systems. In: Craig, Harris \& Weiner (eds.) - Community Participation and Geographic Information Systems, p.1-18, Taylor and Francis, London, U.K.. ISBN: 9780415237529. Disponível em: http://www.spatial.maine.edu/ - onsrud/ Spoleto/WeinerEtAl.pdf

Zamboni, A.; Nicolodi, J.L. (org.) (2008) - Macrodiagnóstico da Zona Costeira e Marinha do Brasil. 242p., Ministério do Meio Ambiente (MMA), Secretaria de Mudanças Climáticas e Qualidade Ambiental, Brasília, DF, Brasil. ISBN 978-8577381128. Disponível em http://www. laget.igeo.ufrj.br/index.php?option $=$ com_content\&task =view\&id=62\&Itemid=2 